\title{
Optimization Studies for Selective Recovery of Phenolics from Wine Wastes
}

\author{
Alexandra Moschona, Maria G. Ziagova, Aliki Iliadou, Maria Liakopoulou-Kyriakides* \\ Faculty of Chemical Engineering, Section of Chemistry, Aristotle University of Thessaloniki, Thessaloniki, Greece \\ Email: "markyr@eng.auth.gr
}

Received 4 March 2016; accepted 15 April 2016; published 19 April 2016

Copyright (C) 2016 by authors and Scientific Research Publishing Inc.

This work is licensed under the Creative Commons Attribution International License (CC BY). http://creativecommons.org/licenses/by/4.0/

(c) (i) Open Access

\begin{abstract}
The objective of the present study was the recovery and selective separation of phenolics from grape marc and lees, two primary wastes from wine-making industry, with solvent extraction method, optimized using One-Factor-at-a-Time method (OFAT) and Response Surface Methodology (RSM). Phenolics from the whole fresh grapes have been studied in previous work, but not the valorization of wine wastes and their phenolic content. Extraction resulted in 19, 15 and $10 \mathrm{mg} / \mathrm{g}$ (dry weight) total phenolics with $96 \%, 87 \%$ and $64 \%$ antioxidant activity from red, white marc and white lees, respectively. Extracts thus obtained were subsequently treated with several sorbents followed by $\mathrm{HCl}$-desorption. $\mathrm{NaOH}$ and $\mathrm{CH} 3 \mathrm{OH}$ treated zeolite and aluminum oxide, respectively, performed better, separating phenolics up to $93 \%$ from total sugars. The latter resulted in a fraction containing up to $50 \%$ of the initial phenolics holding the antioxidant activity (up to $85 \%$ ) of the initial extract. The results indicate the significance of the applied methodology being fast and low cost for the selective recovery of phenolics from wine wastes.
\end{abstract}

\section{Keywords}

Wine Wastes, Phenolics, Antioxidant Activity, Sorption, Response Surface Methodology

\section{Introduction}

In the last few years diminishing the environmental impact of industrial wastes has been a subject of increasing concern. Grapes are one of the world's largest fruit crops and wine-making wastes are rich in phenols. These and other organic compounds also contained considerably increase biochemical and chemical oxygen demands, with detrimental effects on the flora and fauna of discharge zones, while in solid residues used as fertilizers, they may inhibit germination properties. On the other hand, grapes, wine, grape seeds and skins extracts are reported

${ }^{*}$ Corresponding author.

How to cite this paper: Moschona, A., Ziagova, M.G., Iliadou, A. and Liakopoulou-Kyriakides, M. (2016) Optimization Studies for Selective Recovery of Phenolics from Wine Wastes. Agricultural Sciences, 7, 187-195.

http://dx.doi.org/10.4236/as.2016.74019 
to exert favourable effects on human health attributed to their phenolic content [1]-[4].

Literature is rich of examples of recovery of antioxidant compounds from natural sources such as oil seeds, nuts, vegetables, fruits, etc. [5]. Phenolics present antioxidant activity and thus are considered as high addedvalue by-products and the employment of low-cost industrial wastes could greatly reduce the production costs and increase the margin profit of these products [6]. Most of the published work referred to phenolics from the whole fresh grapes [2] [7], whereas recent ones, but few, dealt with valorization of wine wastes and their phenolic content [8] [9]. Based on the above, we undertook an investigation on the recovery of specific bioactive phenolics from grape wastes, which were produced in large amounts in wineries all over Greece.

Solvent extraction methods followed by sorption on specific sorbent materials were chosen. The parameters which influenced the yield of phenolics extraction from wine wastes, such as the solvent type, solid to solvent ratio, $\mathrm{pH}$ value, extraction time and temperature were studied, applying One-Factor-at-a-Time (OFAT) experiments each time while keeping others fixed.

When many factors and interactions affect desired parameter, response surface methodology (RSM) is an effective tool for optimizing the process [10]. RSM is one of the most commonly used Design of Experiments (DoE) technique for the optimization of complex processes. It uses quantitative data from an appropriate experimental design to determine and simultaneously solve multivariate equation. Central Composite Design (CCD) is a widely used response surface design when the experimental region is defined by the upper and lower limits of each factor and not extended beyond them [11]. Optimization of solvent extraction method was also attempted in our study using RSM where the simultaneous effect of three independent variables (pH value, solid to solvent ratio, temperature) were investigated to maximize the recovery of phenolics and their antioxidant activity.

Although organic solvents are useful for the extraction of metabolites from plants, further purification, in order to selectively obtain concentrated specific components, can be essential. Adsorption is preferred by many researchers among others as a low-cost separation technique [12]. Various sorbent materials have been used for selective separation of phenolics, such as resins or activated carbon forms from several sources such as spinach, apple pomace or grape pomace [13] [14]. Apart from that, zeolites and alumina have been also used as sorbents [12] [15]-[18].

The results from the optimized solvent extraction, followed by sorption and subsequent desorption regarding phenolics and their antioxidant activity, are reported here.

\section{Materials and Methods}

\subsection{Materials}

Grape marc and lees (Malagouzia, white local variety and Syrah, red variety) were kindly provided by "Ktima Gerovassiliou”, a wine-making factory in Epanomi (Thessaloniki, Greece) in the vintage 2013. Grape marc samples were collected after pressing and consisted of skin and seeds mainly, whereas white lees were collected before fermentation. Samples were dried at ambient temperature in a desiccator and milled in a commercial blender (i.d. $\leq 1 \mathrm{~mm}$ ).

\subsection{Extraction}

Grape marc and lees (100 g dry weight) were extracted with a certain volume of solvent in a sonicator bath (General sonic, $41 \mathrm{kHz}, 320 \mathrm{~W}$, thermostatically adjustable) at the temperature and the time established. The influence of various parameters ( $\mathrm{pH}$, temperature, solvent type, extraction time and solid to solvent ratio) on the extraction efficiency of phenolic compounds was investigated. The extracts thus obtained, here after called crude extracts, were centrifuged $(4500 \mathrm{rpm}, 10 \mathrm{~min})$, stored in the refrigerator $\left(-20^{\circ} \mathrm{C}\right)$ and further analyzed.

\subsection{Determination of Phenols, Sugar Content and Antioxidant Activity}

Total phenolic content was determined using the Folin-Ciocalteu method and measuring the absorbance of the blue complex formed at $745 \mathrm{~nm}$ [19]. Total phenolics content (TPC) was expressed as mg of gallic acid $\mathrm{g}^{-1}$ (dry weight).

Sugars were determined photometrically by measuring the absorbance at $575 \mathrm{~nm}$, using dinitrosalicylic acid method [20]. 
Antioxidant activity was estimated using the 2,2-diphenyl-1-picrilhydrazyl (DPPH) method with modifications [21]. The DPPH solution $\left(0.1 \mathrm{~g} \cdot \mathrm{L}^{-1}\right.$ in ethanol) was prepared daily, stored in a flask covered with aluminum foil and kept in the dark at $4^{\circ} \mathrm{C}$ between measurements. The percent decrease in absorbance (equation 1) was recorded for each concentration and percent quenching of DPPH radical was calculated on the basis of the observed decrease in absorbance of the radical.

$$
\text { \%Inhibition }=\left[\left(\mathrm{A}_{\mathrm{DPPH}}-\mathrm{A}_{\mathrm{Extr}}\right) / \mathrm{A}_{\mathrm{DPPH}}\right] * 100
$$

where $A_{D P P H}$ is the absorbance value of the DPPH blank sample and $A_{E x t r}$ is the absorbance value of the test solution.

\subsection{Sorbents}

The sorption of phenolic compounds from wine wastes samples was carried out using different organic and inorganic materials, namely, aluminum oxide, zeolite, ash, agar, activated carbon, resins XAD-2, XAD-7 and XAD-16 (Sigma Chemicals). The clinoptilolite-rich mineral (zeolite) (particle size $200 \mu \mathrm{m}$ ) was obtained from Metaxades, Thessaloniki. Treatment of zeolitic samples was carried out using $2 \mathrm{M} \mathrm{NaOH}$ under continuous stirring for $24 \mathrm{~h}$. After that, the solid phase was separated by filtration, washed with deionised water and dried in an oven at $60^{\circ} \mathrm{C}$ over night. Aluminum oxide was stirred with pure methanol for $20 \mathrm{~min}$, centrifuged (4500 rpm, 10 min) and dried over night in a desiccator before use.

\subsection{Sorption/Desorption Experiments}

Batch sorption experiments were conducted by stirring $0.02 \mathrm{~L}$ of extract from marc or lees samples with $0.5 \mathrm{~g}$ of sorbent at ambient temperature. The effect of contact time (up to $2 \mathrm{~h}$ ), $\mathrm{pH}$ (2.0 to 10.0) and sorbent concentration $\left(5,10,19,25\right.$ and $\left.50 \mathrm{~g} \cdot \mathrm{L}^{-1}\right)$ was examined. Samples were centrifuged (4500 rpm, $10 \mathrm{~min}$ ) and the supernatant was analyzed for phenolics, radical scavenging activity and sugar content.

In case of zeolite and aluminium oxide, another series of sorption experiments were conducted, using pre-treatment zeolitic and of aluminum oxide samples as described above.

Desorption experiments, were conducted with $0.1 \mathrm{M} \mathrm{HCl}$. The effect of contact time was examined here also (up to $2 \mathrm{~h}$ ) and the desorbed phenolics, their radical scavenging activity (DPPH inhibition \%) was determined as previously described.

\subsection{Experimental Design Applied to Extraction Procedure and Statistical Analysis}

The individual and interactive effects of the mass to solvent ratio $\left(0.0625-0.1000 \mathrm{~g} \cdot \mathrm{mL}^{-1}\right)$, the temperature $\left(35^{\circ} \mathrm{C}-60^{\circ} \mathrm{C}\right)$ and the $\mathrm{pH}$ value $(2.0-6.5)$ on the total phenolics extracted $\left(\mathrm{mg}^{-1} \mathrm{~g}^{-1}\right) \mathrm{Y} 1$ and the antiradical activity (\%) Y2 as response variables were studied, using RSM [22]. Twenty experiments were performed using a face-centered central composite statistical design for the study of the three independent variables. The levels of the variables were chosen after a series of preliminary experiments.

A second order polynomial model was fitted for the total phenolics extracted and antiradical activity (Y), giving the equation 2 of the following form:

$$
\mathrm{Y}=\mathrm{b}_{0}+\mathrm{b}_{1} \mathrm{X}_{1}+\mathrm{b}_{2} \mathrm{X}_{2}+\mathrm{b}_{3} \mathrm{X}_{3}+\mathrm{b}_{11} \mathrm{X}_{12}+\mathrm{b}_{22} \mathrm{X}_{22}+\mathrm{b}_{33} \mathrm{X}_{32}+\mathrm{b}_{12} \mathrm{X}_{1} \mathrm{X}_{2}+\mathrm{b}_{13} \mathrm{X}_{1} \mathrm{X}_{3}+\mathrm{b}_{23} \mathrm{X}_{2} \mathrm{X}_{3}
$$

where $X_{1}, X_{2}, X_{3}$ represent the actual levels of the independent variables and $b_{0}, b_{i}, b_{i j}(i, j=1,2,3)$ the coefficient estimates, where $b_{0}$ is the interception, $b_{1}$ the linear terms, $b_{2}$ the quadric terms and $b_{3}$ is the interaction terms.

Statistical analysis was carried out using the MINITAB ${ }^{\mathrm{TM}}$ statistical software (17.1.0.0). All experiments were run in triplicate and the results expressed as mean \pm standard deviation (SD) values. All data were considered statistical significant at $\mathrm{p}<0.05$.

\section{Results and Discussion}

\subsection{Optimization of the Extraction Conditions}

The effect of various solvents such as methanol, ethanol, water and mixtures of them on the production of ex- 
tracts with the highest total phenolic content was examined. It was found that methanol and ethanol resulted in red and white marc extracts with the maximum values of TPC. Water and chloroform extracts presented lower values of total phenolics content, which is also in agreement with the lower values of antiradical activity (data obtained but not shown). Ethanol was finally selected as the most appropriate solvent, according to Food and Drug Administration, for the extraction of phenolics. Though, in a recent study [23], the use of methanolic extracts comparing to aqueous or ethanolic extracts has been also reported.

A sample with solid to solvent ratio of $1 / 30$ and 1/5 for grape marc (red and white) and lees (white) respectively, was finally selected. At higher values of this ratio the lower extraction efficiency observed, probably due to mass transfer limitations [2].

Regarding extraction time, it was found that 2 cycles of $20 \mathrm{~min}$ in a sonicator bath were enough for the highest recovery of antioxidant compounds (22.0, 18.0 and $13.0 \mathrm{mg} \cdot \mathrm{g}^{-1}$ for red, white marc and white lees respectively), whereas $80 \%$ of the total phenolics was recovered at the first cycle.

Optimum extraction temperature was estimated at $35^{\circ} \mathrm{C}$ (data obtained but not shown). No significant differences were observed at higher temperatures up to $60^{\circ} \mathrm{C}$ and this is in agreement with previous reports [2] [24] [25].

The effect of $\mathrm{pH}$ on extraction procedure also tested and it was found that acidic hydrolysis at $\mathrm{pH} 2.0$ using $\mathrm{HCl}$, improves further the recovery of phenolic compounds [26]. The final phenolic content at the conditions resulted in $2.2 \%, 1.8 \%$ and $1.3 \%$ for red, white marc and white lees respectively. Interesting, sugars in the same fractions varied from 1.0 for red marc to almost $38 \%$ - $43 \%$ for the other two samples.

Optimization of solvent extraction using OFAT methodology was followed by RSM. The surface plots obtained by applying RSM for total phenolics content $\left(\mathrm{mg} \cdot \mathrm{g}^{-1}\right)$ and antiradical activity (\%) are shown in Figure 1 and Figure 2 respectively for red marc extract based on the three parameters examined (solid to solvent ratio $\mathrm{m} / \mathrm{V}, \mathrm{pH}$ and temperature). Similar results were obtained with white marc, while differences were noticed with lees where $\mathrm{m} / \mathrm{V}$ was $1 / 10 \mathrm{~g} \cdot \mathrm{mL}^{-1}$, and temperature $60^{\circ} \mathrm{C}$.

Table 1 gives the total phenolics content and their antioxidant activity of all wastes extracts examined using RSM and OFAT method, respectively. Small differences observed among the two methodologies can be explained, since OFAT does not include the interactions among the parameters [27]. It is worth mentioning, that RSM values, were close to the predicted responses, verifying the validity of the model.

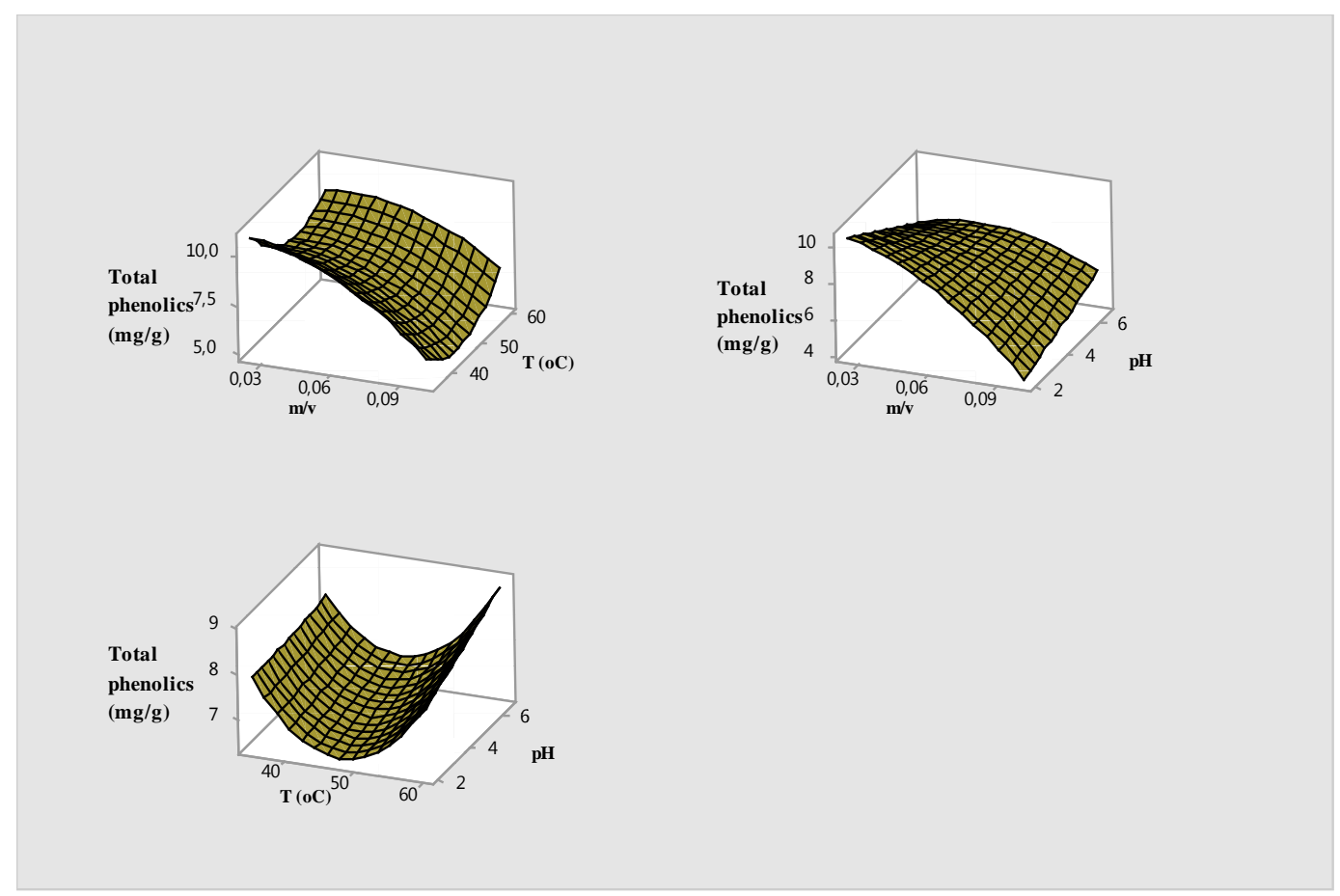

Figure 1. Surface plots of total phenolics content $\left(\mathrm{mg}^{-\mathrm{g}^{-1}}\right)$ of red marc ethanolic extracts, as a function of $\mathrm{pH}$, temperature $\left({ }^{\circ} \mathrm{C}\right)$ and solid to solvent ratio $\left(\mathrm{g} \cdot \mathrm{mL}^{-1}\right)$. 


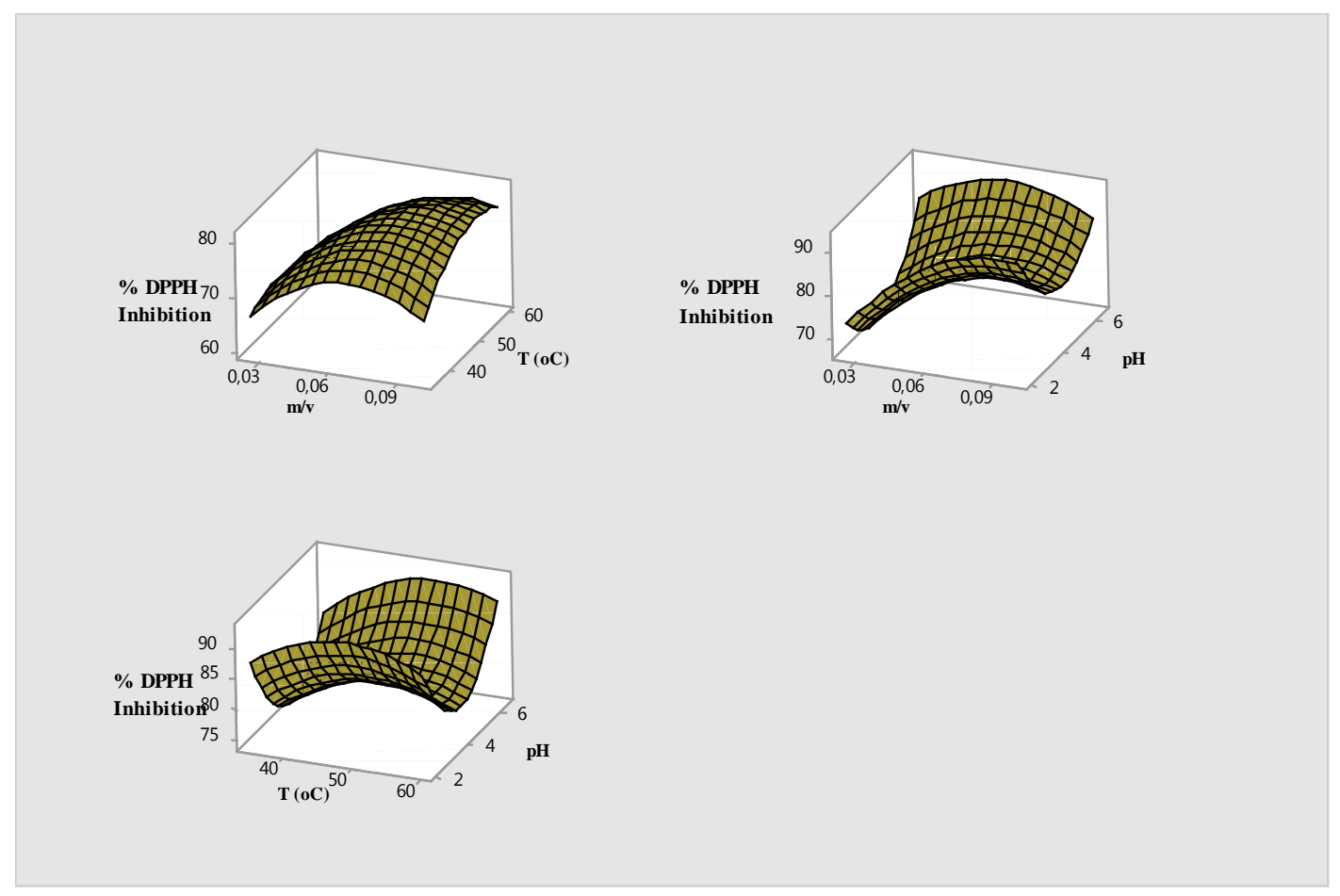

Figure 2. Surface plots of antiradical activity (\%) of red marc ethanolic extracts as a function of $\mathrm{pH}$, temperature $\left({ }^{\circ} \mathrm{C}\right)$ and solid to solvent ratio $\left(\mathrm{g} \cdot \mathrm{mL}^{-1}\right)$.

Table 1. Total phenolics versus their antioxidant activity recovered at the optimum conditions determined with RSM and OFAT method.

\begin{tabular}{ccc}
\hline & Total phenolics $\left(\mathbf{m g} \cdot \mathbf{g}^{-1}\right)^{*}$ & \% Inhibition of DPPH* \\
\hline Red Marc & & \\
\hline RSM predicted & 18 & $96 \pm 2.02$ \\
Observed & $19.00 \pm 2.01$ & $94 \pm 2.12$ \\
OFAT determined & $22.00 \pm 2.69$ & 92 \\
\hline White Marc & & $87 \pm 1.92$ \\
\hline RSM predicted & 18 & $91 \pm 1.73$ \\
\hline Observed & $15.00 \pm 1.11$ & 58 \\
OFAT determined & $18.00 \pm 1.73$ & $64 \pm 1.67$ \\
\hline White Lees & & $65 \pm 2.74$ \\
\hline RSM predicted & 11 & \\
\hline Observed & $10.00 \pm 0.97$ & \\
\hline OFAT determined & $13.00 \pm 2.72$ & \\
\hline
\end{tabular}

* Each value is presented as mean $\pm \mathrm{SD}(\mathrm{n}=3)$; ** All data were statistical significant at $p<0.05$.

\subsection{Sorption-Desorption Studies}

Various sorbents were tested in order to recover phenolics from initial extracts obtained as described above (Figure 3). Only zeolite and aluminium oxide were found selective towards phenolics, whereas desorption was also feasible. Activated carbon, ash and PVPP sorbed phenolics selectively, but their binding to sorbent surface was irreversible making their desorption negligible.

In an attempt to improve zeolite's and aluminum oxide's sorption capacity, pre-treatment with $\mathrm{NaOH}$ and $\mathrm{CH} 3 \mathrm{OH}$ respectively was performed. As it can be seen from Figure 4, phenolics sorption was enhanced in both 


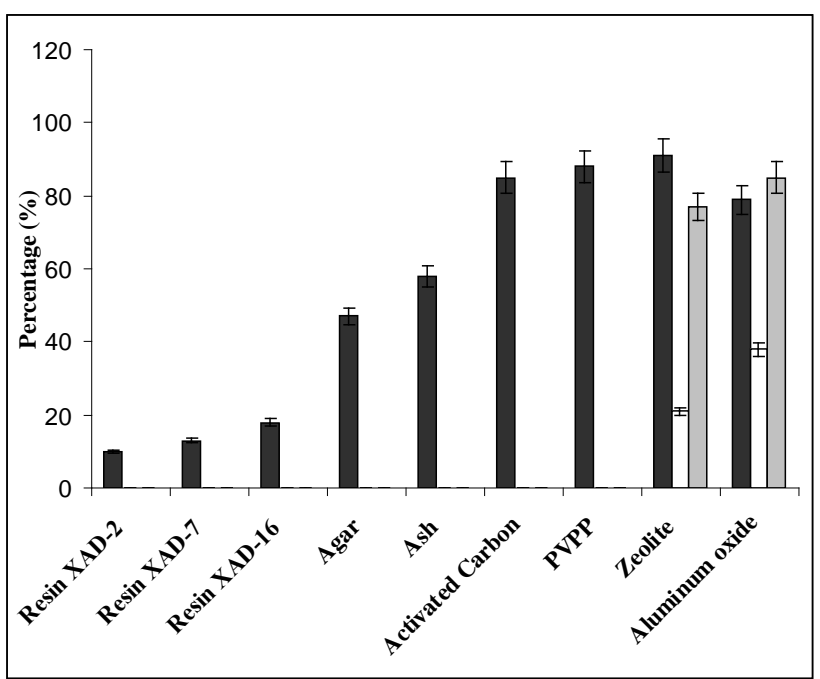

Figure 3. Effect of various sorbents tested in sorption ( $\square)$, desorption ( $\square$ ) of phenolics and antioxidant activity $(\square)$ of white marc ethanolic extracts, at w/v 1/30, pH 6.5, contact time $2 \mathrm{~h}$. All data were statistical significant at $p<0.05$.

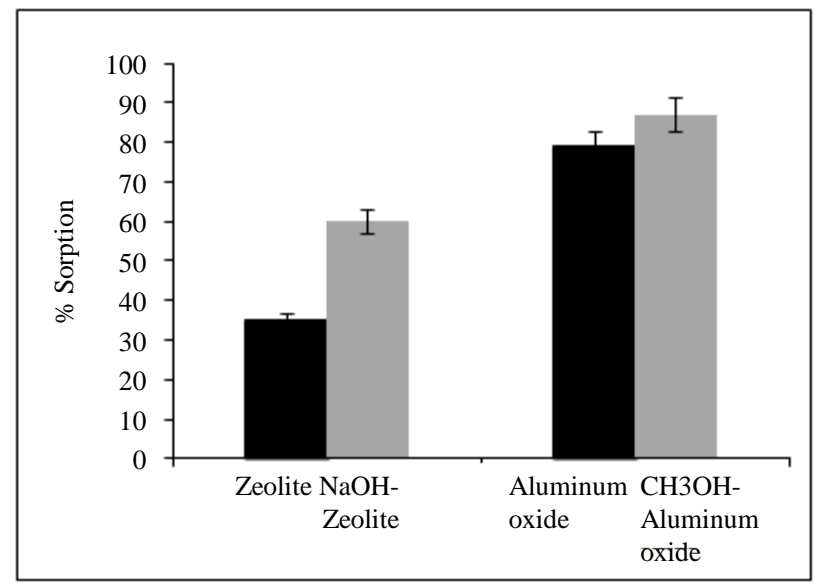

Figure 4. Effect of sorbent treatment on phenolics sorption after $24 \mathrm{~h}$ using non-treated aluminium oxide and zeolite as well as $\mathrm{NaOH}$-treated zeolite and $\mathrm{CH}_{3} \mathrm{OH}$-treated aluminium oxide $(\mathrm{pH}$ 6.5 , sorbent concentration $25 \mathrm{~g} \cdot \mathrm{L}^{-1}$ ). All data were statistical significant at $p<0.05$.

cases and sorbent selectivity towards sugars was also increased. Treatment of zeolite with $\mathrm{NaOH}$ aqueous solution leads to negative charge of its surface (by reaction $\mathrm{SiOH}+\mathrm{OH}^{-}=\mathrm{SiO}^{-}+\mathrm{H}_{2} \mathrm{O}$ ) and thus phenolics sorption occurs via hydrogen-bonding between this oxygen site and hydroxyl groups of phenols [28].

Sorption $\mathrm{pH}$ is another important parameter affecting the surface charge of the adsorbents as well as the ionization degree of the sorbate [29]. It was found that in a certain pH range (from 2.0 to 6.5) sorption of most phenolics from all wine extracts was increased from $42 \%$ to $68 \%$ and from $38 \%$ to $93 \%$ using $\mathrm{NaOH}$-zeolite and $\mathrm{CH} 3 \mathrm{OH}$-aluminum oxide respectively. At higher $\mathrm{pH}$ values (at $\mathrm{pH}$ 10.0), formation of a precipitate was observed that was completely dissolved when acidity was reached. This precipitate may be formed due to alteration of chromophoric characteristics under alkaline conditions [30]-[32].

The sorption percentage of phenolics increased from 10 to $96 \%$ by increasing the adsorbent concentration from $5 \mathrm{~g} \cdot \mathrm{L}^{-1}$ to $50 \mathrm{~g} \cdot \mathrm{L}^{-1}$ for white marc extracts. Similar performance was observed with red marc and white lees (data not shown). This may be due to higher number of the available adsorption sites by increasing the sor- 
bent concentration and therefore resulting in higher removal efficiency. Desorption of phenolics followed the same pattern as that of sorption, where at $25 \mathrm{~g} \cdot \mathrm{L}^{-1}$ adsorbent concentration, the maximum phenolic content, possessing high values of the antioxidant activity as well, was recovered with both adsorbents. More specifically, their radical scavenging activity preserved after desorption and ranged between $68 \%$ and $85 \%$ depending on the type of wine waste used, where red and white marc prevail towards white lees.

Regarding the time profile given in Figure 5, it was found that adsorption of phenolics reached equilibrium within 15 min using $\mathrm{CH} 3 \mathrm{OH}$-treated aluminum oxide. Therefore, considering economic and practical aspects, contact time of 30 min was employed in all subsequent experiments to ensure that equilibrium time was attained. Desorption was also fast, where 15 min needed so as equilibrium to be reached (data obtained but not shown).

Table 2 shows the values of total sugars, phenolics and antioxidant activity of extracts before and after sorption and desorption experiments. Sugars percentage estimated in the desorbed material, was between $5 \%$ and $14 \%$ for white lees and marc respectively, whereas in red marc mixtures, sugars had been completely removed, suggesting these two sorbents as appropriate for sorption of phenols. The data in this Table also show that despite the low percentages of the eluted phenolics $(0.45 \%, 0.2 \%$ and $0.6 \%$ of the extract of red, white marc and white lees respectively), the isolated fractions retain high levels of initial antioxidant activity (69\% to $85 \%$ ). This is very significant finding since desorption elutes only the most of the active phenols, leaving the majority of inactive ones still on the surface of sorbent materials. The desorbed phenolics, as high-added value products may have applicability in food and pharmaceutical industry. The contribution of the major constituents of the obtained fractions, to antioxidant as well as to other biological activities as a result of synergism is under current investigation.

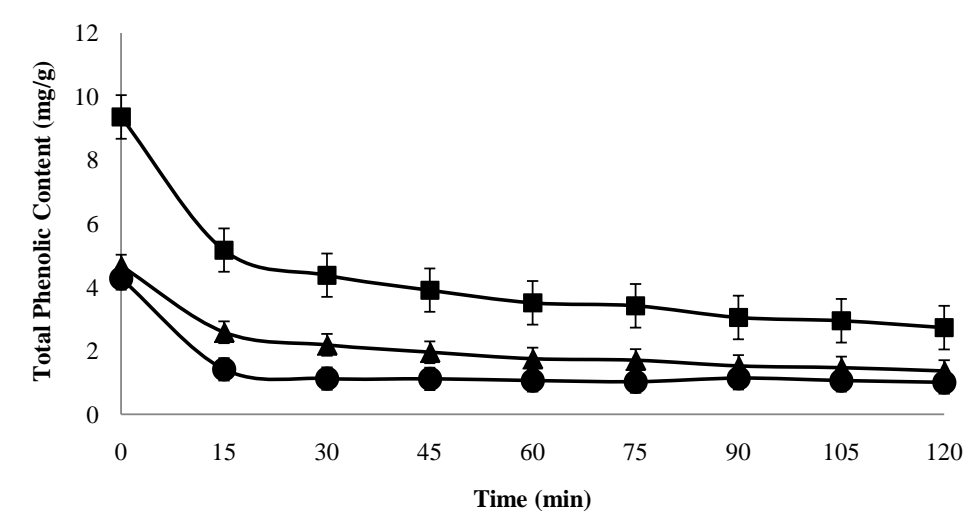

Figure 5. Effect of time on total phenolics content in the supernatant after sorption with $\mathrm{CH}_{3} \mathrm{OH}$-aluminum oxide using red marc (-๑-), white marc (--) at pH 6.5 and white lees (- $\left.\boldsymbol{\Delta}_{-}\right)$at $\mathrm{pH} 10.0$ (adsorbent concentration $\left.25 \mathrm{~g} \mathrm{~L}^{-1}\right)$. All data were statistical significant at $p<0.05$.

Table 2. Total sugars, phenolics and their antioxidant activity recovered after desorption with $0.1 \mathrm{M} \mathrm{HCl}$ using $\mathrm{CH}_{3} \mathrm{OH}-$ treated aluminium oxide and $\mathrm{NaOH}$-treated zeolite respectively. **

\begin{tabular}{|c|c|c|c|c|}
\hline \multicolumn{2}{|c|}{ Samples } & $\begin{array}{l}\text { Total Sugars } \\
\left(\mathrm{mg} \cdot \mathrm{g}^{-1}\right)^{*}\end{array}$ & $\begin{array}{c}\text { TPC } \\
\left(\mathbf{m g} \cdot \mathrm{g}^{-1}\right)^{*}\end{array}$ & \% Inhibition of DPPH* \\
\hline \multirow{3}{*}{$\begin{array}{l}\text { Crude } \\
\text { Extracts }\end{array}$} & Red marc & $10.00 \pm 0.91$ & $19.00 \pm 2.01$ & $96 \pm 2.02$ \\
\hline & White marc & $380.00 \pm 10.02$ & $15.00 \pm 1.11$ & $87 \pm 1.92$ \\
\hline & White lees & $430.00 \pm 14.20$ & $10.00 \pm 0.97$ & $64 \pm 1.67$ \\
\hline \multirow{3}{*}{$\begin{array}{l}\text { After desorption } \\
\text { from } \mathrm{NaOH} \text {-Zeolite }\end{array}$} & Red marc & $1.00 \pm 0.02$ & $1.05 \pm 0.04$ & $70 \pm 1.15$ \\
\hline & White marc & $28.00 \pm 1.82$ & $2.32 \pm 0.19$ & $77 \pm 0.82$ \\
\hline & White lees & $60.00 \pm 4.02$ & $1.66 \pm 0.04$ & $70 \pm 2.05$ \\
\hline \multirow{3}{*}{$\begin{array}{c}\text { After desorption } \\
\text { from } \\
\mathrm{CH}_{3} \mathrm{OH} \text {-Aluminum } \\
\text { oxide }\end{array}$} & Red marc & $1.00 \pm 0.02$ & $4.46 \pm 0.13$ & $75 \pm 3.02$ \\
\hline & White marc & $27.00 \pm 1.00$ & $2.00 \pm 0.22$ & $85 \pm 2.62$ \\
\hline & White lees & $59.00 \pm 3.32$ & $5.53 \pm 0.25$ & $69 \pm 3.09$ \\
\hline
\end{tabular}

* Each value is presented as mean $\pm \mathrm{SD}(\mathrm{n}=3)$; ** All data were statistical significant at $p<0.05$. 


\section{Conclusion}

Optimized solvent extraction followed by sorption/desorption is proposed here as fast and low cost methodology for the recovery of high-added value phenolics in terms of their radical scavenging activity from wine wastes. The optimum conditions of phenolics extraction, from grape marc and lees, using RSM and OFAT method, were in good agreement. Also, pre-treated, as reported above, of zeolite and aluminum oxide respectively, were selective not only towards phenolic compounds but to sugars as well, based on the studied wine wastes. In conclusion, wine wastes after extraction and subsequent sorption/desorption resulted in the recovery of certain phenolic fractions preserving the $85 \%$ of initial antioxidant activity. The results, by applying fast and low cost technique to obtain added value phenolics are of real importance and may have several applications in food and pharmaceutical industry. The contribution of the major constituents of the obtained fractions, to antioxidant as well as to other biological activities as a result of synergism is under current investigation.

\section{Acknowledgements}

The authors would like to thank the winery "Ktima Gerovassiliou” for providing wine waste samples of white and red vinification.

The research work was supported by “11SYN_2_1992” action “COOPERATION 2011” of EYDE-ETAK funded by the Operational Program “Competitiveness and Entrepreneurship” (EPAN-II).

\section{References}

[1] Lafka, T.-I., Sinanoglou, V. and Lazos, E.S. (2007) On the Extraction and Antioxidant Activity of Phenolic Compounds from Winery Wastes. Food Chemistry, 104, 1206-1214. http://dx.doi.org/10.1016/j.foodchem.2007.01.068

[2] Spigno, G. and De Faveri, D.M. (2007) Antioxidants from Grape Stalks and Marc: Influence of Extraction Procedure on Yield, Purity and Antioxidant Power of the Extracts. Journal of Food Engineering, 78, 793-801. http://dx.doi.org/10.1016/j.jfoodeng.2005.11.020

[3] Xia, E.-Q., Deng, G.-F., Guo, Y.-J. and Li, H.-B. (2010) Biological Activities of Polyphenols from Grapes. International Journal of Molecular Sciences, 11, 622-646. http://dx.doi.org/10.3390/ijms11020622

[4] Rockenbach, I.I., Rodrigues, E., Gonzaga, L.V., Caliari, V., Genovese, M.I., Gonçalves, A.E.S.S. and Fett, R. (2011) Phenolic Compounds Content and Antioxidant Activity in Pomace from Selected Red Grapes (Vitis vinifera L. and Vitis labrusca L.) Widely Produced in Brazil. Food Chemistry, 127, 174-179. http://dx.doi.org/10.1016/j.foodchem.2010.12.137

[5] Brewer, M. (2011) Natural Antioxidants: Sources, Compounds, Mechanisms of Action, and Potential Applications. Comprehensive Reviews in Food Science and Food Safety, 10, 221-247. http://dx.doi.org/10.1111/j.1541-4337.2011.00156.x

[6] Soto, M.L., Conde, E., González-López, N., Conde, M.J., Moure, A., Sineiro, J. and Parajó, J.C. (2012) Recovery and Concentration of Antioxidants from Winery Wastes. Molecules, 17, 3008-3024. http://dx.doi.org/10.3390/molecules17033008

[7] Louli, V., Ragoussis, N. and Magoulas, K. (2004) Recovery of Phenolic Antioxidants from Wine Industry By-Products. Bioresource Technology, 92, 201-208. http://dx.doi.org/10.1016/j.biortech.2003.06.002

[8] Aizpurua-Olaizola, O., Ormazabal, M., Vallejo, A., Olivares, M., Navarro, P., Etxebarria, N. and Usobiaga, A. (2015) Optimization of Supercritical Fluid Consecutive Extractions of Fatty Acids and Polyphenols from Vitis vinifera Grape Wastes. Journal of Food Science, 80, 101-107. http://dx.doi.org/10.1111/1750-3841.12715

[9] Mateo, J.J. and Maicas, S. (2015) Valorization of Winery and Oil Mill Wastes by Microbial Technologies. Food Research International, 73, 13-25. http://dx.doi.org/10.1016/j.foodres.2015.03.007

[10] Rastogi, N.K., Rajesh, G. and Shamala, T.R. (1998) Optimization of Enzymatic Degradation of Coconut Residue. Journal of the Science of Food and Agriculture, 76, 129-134. http://dx.doi.org/10.1002/(SICI)1097-0010(199801)76:1<129::AID-JSFA909>3.0.CO;2-C

[11] Matsakidou, A., Mantzouridou, F.Th. and Kiosseoglou, V. (2015) Optimization of Water Extraction of Naturally Emulsified Oil from Maize Germ. LWT-Food Science and Technology, 63, 206-213. http://dx.doi.org/10.1016/j.lwt.2015.03.039

[12] Lin, S.-H. and Juang, R.-S. (2009) Adsorption of Phenol and Its Derivatives from Water Using Synthetic Resins and Low-Cost Natural Adsorbents: A Review. Journal of Environmental Management, 90, 1336-1349. http://dx.doi.org/10.1016/j.jenvman.2008.09.003 
[13] Soto, M.L., Moure, A., Domínguez, H. and Parajó, J.C. (2011) Recovery, Concentration and Purification of Phenolic Compounds by adsorption: A Review. Journal of Food Engineering, 105, 1-27. http://dx.doi.org/10.1016/j.jfoodeng.2011.02.010

[14] Kramer, M., Bruns, R.A., Sedlatschek, R., Carle, R. and Kammerer, D.R. (2012) Evaluation of the Adsorption Behavior of Polyacetylenes onto a Food-Grade Resin for the Debittering of Carrot Juice. European Food Research and Technology, 234, 779-787. http://dx.doi.org/10.1007/s00217-012-1686-y

[15] Damjanović, L., Rakić, V., Rac, V., Stošić, D. and Auroux, A. (2010) The Investigation of Phenol Removal from Aqueous Solutions by Zeolites as Solid Adsorbents. Journal of Hazardous Materials, 184, 477-484. http://dx.doi.org/10.1016/j.jhazmat.2010.08.059

[16] Yousef, R.I., El-Eswed, B. and Ala, H. (2011) Adsorption Characteristics of Natural Zeolites as Solid Adsorbents for Phenol Removal from Aqueous Solutions: Kinetics, Mechanism, and Thermodynamics Studies. Chemical Engineering Journal, 171, 1143-1149. http://dx.doi.org/10.1016/j.cej.2011.05.012

[17] Akhlaghian, F., Ghadermazi, M. and Chenarani, B. (2014) Removal of Phenolic Compounds by Adsorption on Nano Structured Aluminosilicates. Journal of Environmental Chemical Engineering, 2, 543-549. http://dx.doi.org/10.1016/j.jece.2013.10.009

[18] Asmaly, H.A., Saleh, T.A., Laoui, T., Gupta, V.K. and Atieh, M.A. (2015) Enhanced Adsorption of Phenols from Liquids by Aluminum Oxide/Carbon Nanotubes: Comprehensive Study from Synthesis to surface Properties. Journal of Molecular Liquids, 206, 176-182. http://dx.doi.org/10.1016/j.molliq.2015.02.028

[19] Singleton, V.L., Orthofer, R. and Lamuela-Raventos, R.M. (1999) Analysis of Total Phenols and Other Oxidation Substrates and Antioxidants by Means of Folin-Ciocalteu Reagent. Methods in Enzymology, 299, 152-178. http://dx.doi.org/10.1016/S0076-6879(99)99017-1

[20] Miller, G.L. (1959) Use of Dinitrosalicylic Acid Reagent for Determination of Reducing Sugar. Analytical Chemistry, 31, 426-428. http://dx.doi.org/10.1021/ac60147a030

[21] Blois, M.S. (1958) Antioxidant Determinations by the Use of a Stable Free Radical. Nature, 181, 1199-1200. http://dx.doi.org/10.1038/1811199a0

[22] Myers, R.H. and Montgomery, D.C. (2002) Response Surface Methodology. Experimental Designs for Fiting Response Surfaces I. Second Edition, John Wiley \& Sons Inc., New York, 303-376.

[23] Annegowda, H., Bhat, R., Min-Tze, L., Karim, A. and Mansor, S. (2012) Influence of Sonication Treatments and Extraction Solvents on the Phenolics and Antioxidants in Star Fruits. Journal of Food Science and Technology, 49, 510-514. http://dx.doi.org/10.1007/s13197-011-0435-8

[24] Cacace, J. and Mazza, G. (2003) Optimization of Extraction of Anthocyanins from Black Currants with Aqueous Ethanol. Journal of Food Science, 68, 240-248. http://dx.doi.org/10.1111/j.1365-2621.2003.tb14146.x

[25] Mildner-Szkudlarz, S., Zawirska-Wojtasiak, R. and Gośliński, M. (2010) Phenolic Compounds from Winemaking Waste and Its Antioxidant Activity towards Oxidation of Rapeseed Oil. International Journal of Food Science \& Technology, 45, 2272-2280. http://dx.doi.org/10.1111/j.1365-2621.2010.02397.x

[26] Madhujith, T. and Shahidi, F. (2009) Effect of Alkaline Hydrolysis of Barley Extracts on Antioxidant Efficacy. Food Chemistry, 117, 615-620. http://dx.doi.org/10.1016/j.foodchem.2009.04.055

[27] Czitrom, V. (1999) One-Factor-at-a-Time versus Designed Experiments. The American Statistician, 53, 126-131.

[28] Sprynskyy, M., Ligor, T., Lebedynets, M. and Buszewski, B. (2009) Kinetic and Equilibrium Studies of Phenol Adsorption by Natural and Modified Forms of the Clinoptilolite. Journal of Hazardous Materials, 169, 847-854. http://dx.doi.org/10.1016/j.jhazmat.2009.04.019

[29] Aravindhan, R., Rao, J.R. and Nair, B.U. (2009) Application of a Chemically Modified Green Macro Alga as a Biosorbent for Phenol Removal. Journal of Environmental Management, 90, 1877-1883. http://dx.doi.org/10.1016/j.jenvman.2008.12.005

[30] Chethan, S. and Malleshi, N. (2007) Finger Millet Polyphenols: Optimization of Extraction and the Effect of pH on Their Stability. Food Chemistry, 105, 862-870. http://dx.doi.org/10.1016/j.foodchem.2007.02.012

[31] Gupta, V.K., Agarwal, S. and Saleh, T.A. (2011) Synthesis and Characterization of Alumina-Coated Carbon Nanotubes and Their Application for Lead Removal. Journal of Hazardous Materials, 185, 17-23. http://dx.doi.org/10.1016/j.jhazmat.2010.08.053

[32] Li, X., Huang, J., Wang, Z., Jiang, X., Yu, W., Zheng, Y. and He, N. (2014) Alkaline Extraction and Acid Precipitation of Phenolic Compounds from Longan (Dimocarpus longan L.) Seeds. Separation and Purification Technology, 124, 201-206. http://dx.doi.org/10.1016/j.seppur.2014.01.030 